\title{
The Play Was Always the Thing: Drama's Effect on Brain Function
}

\author{
Brian H. Hough ${ }^{1}$, Sigmund Hough ${ }^{2}$ \\ ${ }^{1}$ Marblehead High School, Marblehead, USA \\ ${ }^{2}$ Department of Psychiatry, Harvard Medical School, Boston, USA \\ Email: Sigmund_Hough@hms.harvard.edu
}

Received March 20 ${ }^{\text {th }}$, 2012; revised April 17 ${ }^{\text {th }}$, 2012; accepted May $16^{\text {th }}, 2012$

\begin{abstract}
The brain is a mysterious canvas of actualized and unrealized possibilities. As Diane Ackerman notes, "...each person carries around atop the body a complete universe in which trillions of sensations, thoughts, and desires stream.” Brain science remains uncharted territory despite the significant efforts that have been and are being realized to better understand brain and behavior. More than mere coincidence or happenstance, plays like Shakespeare's famous "Romeo and Juliet” with great storylines, brilliant costumes, and emotional stimulation continue to survive for ages based upon pure artistic excellence that engages the audience in a unique manner. There is a need to more fully understand how our brains process drama and the manner in which like versus dislike are decided. Most important is the factor of longevity and what makes the appealing quality of drama survive over years across cultural and generational shifts. To speak to this question, drama has been shown to have impressive effects on brain activation but remains conservative in highlighting potentially profound implications. Drama has advantageous benefits to health as well as to essential activities such as learning and personal growth. Drama should not remain underrated in terms of its influence on brain function and the relationship between environment and brain.
\end{abstract}

Keywords: Art; Brain Function; Brain Stimulation; Drama; Shakespeare

\section{The Brain}

The brain is a mysterious canvas of actualized and unrealized possibilities. As Diane Ackerman notes, “...each person carries around atop the body a complete universe in which trillions of sensations, thoughts, and desires stream.” Brain science remains uncharted territory despite the significant efforts that have been and are being realized to better understand brain and behavior. More than mere coincidence or happenstance, plays like Shakespeare's famous "Romeo and Juliet” with great storylines, brilliant costumes, and emotional stimulation continue to survive for ages based upon pure artistic excellence that engages the audience in a unique manner. There is a need to more fully understand how our brains process drama and the manner in which like versus dislike are decided. Most important is the factor of longevity and what makes the appealing quality of drama survive over years across cultural and generational shifts. To speak to this question, drama has been shown to have impressive effects on brain activation but remains conservative in highlighting potentially profound implications. Drama has advantageous benefits to health as well as to essential activities such as learning and personal growth. Drama should not remain underrated in terms of its influence on brain function and the relationship between environment and brain.

Humans interact with each other, but the way in which each individual interacts differs greatly. The way people live their lives differs in this way as well. This is primarily due to a combination of different brain compositions, personality traits and cultural-environmental conditions. As Pinker (1997: p. 62) stated, "Intelligence... is the ability to attain goals in the face of obstacles by means of decisions based on rational (truth-obeying) rules." However, intelligence is different from thought as "Humans...emit a response to a stimulus either because it was earlier paired with a reflexive trigger for that response...or because the response was rewarded in the presence of that stimulus” (Pinker, 1997: p. 62). Stimuli trigger responses that include action, non-action, covert, and overt behavior. As humans age and therefore accumulate more life experiences, humans learn how to more efficiently react to different stimuli under different conditions. This is especially true with the prefrontal cortex. This part of the brain deals with executive functioning and is not fully developed until at least 21 years of age. Until then, adolescents rely on "fight or flight" hormones and neurotransmitters such as adrenaline and the amygdala (the emotional control center of the brain) to react with their world, while adults can more efficiently sort out stimuli.

\section{Drama and the Brain}

We know that stimuli can affect human behaviors. Steven Pinker (1997: p. 62) illustrates how this condition occurs because "when shocked, refreshed, or just learning something, neurons grow new dendritic branches, increasing their reach and influence even more. The neurotransmitter travels from neuron to neuron through the use of an axon and across a synapse. As the axon's tip grows, it senses its environment, getting cues on which direction to turn. Somehow all that nosing around, connecting, and networking orients personality, chisels character.” Accordingly, this neurologic process contributes to the shaping of cognitive and emotional thought. Drama is thus entertaining and captivating because to act in a way different from usual requires response to a novel set of stimuli. New 
neurons and axon tips grow during this process of development and adaptation. This process of becoming different is interesting to the brain because of the inherent ability to make change to serve a new purpose.

\section{The Impact of Drama}

At the University of Liverpool (2006), research has shown that reading William Shakespeare's works stimulates the brain. Shakespeare's works create functional shifts for the brain, which "...[allow] the brain to understand what a word means before [the brain] understands the function of the word within a sentence... [This causes] ... a sudden peak in brain activity and forces the brain to work backwards in order to fully understand what Shakespeare is trying to say.” This brain function does not happen easily and due to this, the brain is affected greatly in an effort to adapt to this new and exciting environment. Drama represents to the brain a challenge which must be managed. Shakespeare's way of “...throwing odd words into seemingly normal sentences, surprises the brain and catches it off guard in a manner that produces a sudden burst of [positive] activity-a sense of drama created out of the simplest of things" (University of Liverpool, 2006). This is paramount to the understanding of how the mind works, relating back to Ackerman's and Pinker's books. Through knowing what creates positive brain waves in the brain, drama could act as a medium for alleviating depression while allowing individuals to develop happy dispositions.

To keep the brain "fit" has become a cliché nowadays, as businesses have attempted to mass-produce brain games/puzzles/activities that are advertised to keep the brain functioning efficiently and clearly for longer periods of time than nature would allow. However, Dave Munger (2007) argues that theater and drama may be the best activity for brain health, while also being enjoyable. In a trial involving 124 older adults (aged 60 to 86), all attended nine 90-minute sessions over a month, where one group was assigned to participate in a theater workshop, one group studied visual art, and one group received no training at all. Each group took an assortment of cognitive tests at the beginning and end of each month. At the end of the trial, the people who participated in theater workshops had a significantly higher change in their scores from their pre-test to their post-test. In the theater group, cognitive test scores testing problem-solving increased the most significantly out of all three of the groups, followed by cognitive tests in word recall, and cognitive tests in psychological well-being. However, memory span increased the most with visual arts, although both visual arts and theater were significantly higher than the control group without training. The author argues that their findings demonstrate that theater training, even during a relatively short time, can help prevent cognitive decline associated with aging. The University of Liverpool's experiment between people in theater workshops, visual arts workshops, or not in any work- shops is noteworthy because in such a short span of time (not more than four weeks), test scores increased greatly due to participation in theater. This research proposes that cognitive decline could be significantly reduced if people are involved in theater or such related activity. Theater could in turn minimize or reduce the risk of brain related diseases since the brain is remaining active and "fit". In a 2004 study at Elmhurst College, a total of 124 participants aged 60 - 86 years were apportioned to one of three groups: theater arts, non-content specific visual arts, or no treatment. After 4 weeks, the adults in the theater arts group improved significantly more than the no-treatment control group in each of the four measures: word recall, memory, problem solving, and psychological well-being. Adults in the visual arts group showed smaller increases relative to the control group. Four months later, the theater group had retained performance improvements across all measures. The authors concluded that theater training, even over a short time period, can help prevent cognitive decline associated with aging (Bell, 2012). The study suggests that cognitive gains may be found from theater participation in as little time as four weeks which is consistent with the study at the University of Liverpool. Due to the creative qualities inherent in drama, the study goes on to say that creative engagement may also improve the quality of life for adults with Alzheimer's disease and other age-related dementias.

Being active and physically fit may just be one of the factors to promote a healthy brain, since "Tip-of-the-tongue memory is more complicated than it seems. Remembering a word takes two steps, pinpointing the word you want and then fetching the sound code for the word" (Ackerman, p. 86). The memory is carried through with the brain's temporal lobe: "the lower lateral lobe of the cerebral hemisphere, lying below the sylvian (lateral) fissure and merging posteriorly with the occipital lobe" (Loring, 1999). The temporal lobe is a critical structure of the brain because the temporal lobe includes the hippocampus which is involved with creating memories (Loring, 1999). "That's why Alzheimer's, an illness that depletes the temporal lobe, [which] begins slowly in a plague of forgetfulness... [and later] attacking all forms of memory" is so devastating (Ackerman, 2004: p. 86). Interestingly, the answer to combat this condition may lie with elements inherent within drama and theater. As Munger and the University of Liverpool have presented, drama may be the answer to stopping or slowing the progressive nature of cognitive decline shown in malicious brain diseases like Alzheimer Disease. Through using the brain in a different way than the brain would be used normally, the mind is forced to think and act abstractly. This abstraction creates positive brain waves through overcoming an obstacle, while increasing brain activity and causing different parts of the brain to be used together in unison. The brain and its functions operate on a "use-it-or-lose-it" basis, and theater and drama cause different parts of the brain to work together. Theater and drama accordingly strengthen the temporal lobe functioning, and potentially reversed or stabilized the effects of cognitive decline and brain disease. There are even reports of utilizing developmental drama for children with brain injury (Martin, 1977). Although this has not been proven, drama and theater are promising steps towards achieving such a goal.

Evidence of drama's dramatic effects on learning has been especially shown in studies teaching impoverished children. Jensen (2010) states that the arts are an often-neglected part of the curriculum that can have a dramatic impact on student performance, as drama teaches emotional intelligence that correlates with higher grades, memorization and processing skills and fosters social status and friends. UCLA professor, Dr. James Catterall (Jensen, 2010) analyzed more than 25,000 students and found that students participating in drama surpass students who do not participate in drama, especially in the fields of reading and mathematics. Also from the study, Dr. Catterall found continued involvement in music and theater to be highly correlated with success in mathematics and reading. 
Furthermore, students from lower socioeconomic status who received music lessons in grades 8 - 12 versus no music lessons increased their math scores significantly as well as improving reading, history, and geography by $40 \%$.

Drama enhances student brains in a manner that sitting in a classroom for six hours cannot provide students. The arts and drama foster an environment for wanting to learn. Christopher Andersen, also, speaks of "greater cognitive gains [with students studying with drama] than students in a traditional classroom environment," (Andersen, 2004):

...these dramas do not sharply distinguish between actor and audience; the learner is both participant and observer, playing a role while interacting with others in role. The drama is facilitated by the classroom teacher, who builds on the actions and reactions of students-in-role to change (or reframe) the imagined context in order to create an episodic sequence of dramatic action.

An environment which fosters teaching and participation with active learning along with first-hand experiences may provide a more productive path for education. Information is taken in, absorbed and encoded through more access points with drama-infused education than learning through receiving information by single methodology. Students, when studying with drama, are constantly involved in their studies (just by the nature of drama) and can therefore, possibly, outperform students who study exclusively in a more traditional type of setting. Education through drama removes a traditional-learning block of academic routine structure and brings learning into a physical realm that can be acted out to be made real to the students. More senses are activated compared to the absorption of knowledge in a classroom. The belief here is that when new knowledge is generated from within an authentic milieu, learning is viewed as more genuine, dynamic and meaningful. Drama may be used as a motivational component to keep children actively involved in their studies. Andersen (2004) later talks of drama's supportive approach, placing responsibility with the students, over a traditional classroom's leading approach, where the teacher directs the students.

\section{Conclusion}

Through a synthesis of research articles and books on the brain, drama, and theater, it is clear that drama affects the brain to a greater degree than one would expect. Overall, drama makes the brain think in a way that is different. Drama creates positive feelings while strengthening the temporal lobe which has been shown to be associated with slow cognitive decline in some cases and a healthier brain is thus maintained for a longer amount of time. Drama provides a disciplined, calm, and hardworking atmosphere which promotes efficient study skills, school success and good memory. In this way, drama cultivates a healthy brain, also showing how the brain strengthens certain brain functions in a use-it-or-lose-it manner. By using the full capacity of the brain, the brain becomes active in more areas and therefore takes longer to decay since more parts of the brain are active. The acceptance of expressive modality into psychotherapy as a means to enhance communication and psychological change can be found in such works as McNiff's (McNiff, 1981). Drama therapy utilizes drama or theatre to accomplish the therapeutic goals of emotion and The Arts and
Psychotherapy physical integration towards personal development and dysfunctional symptom relief (Malchiodi, 2006). Scheff opinioned that people seek and enjoy activities that allow them to symbolically re-experience their own agonizing emotional experiences, which brings relief or closure on issues (Scheff, 2001). There are even early reports that the Egyptians encouraged people with mental illness to participate in artistic activity (Fleshman \& Fryrear, 1981). Revisiting a historical precedence provides a perspective that we have been aware of the relationship of drama and mental health functioning over hundreds of years.

Still, there is a need for further investigation involving more empirical studies to examine the claims of previously cited investigations and studies. While we wait for additional evidence-based analysis, the pure enjoyment that improves one's attitude and outlook on life is certainly compelling to continue the play. The brain is the key to understanding the human universe, and decoding how the mind works would be groundbreaking. We are nowhere near that achievement at this time, but evidence has proven that there are hidden, potential benefits to drama waiting to be discovered. Based upon the literature, drama and theater highlight a bright path for understanding the brain and all that the brain can do, and warrants further research.

\section{REFERENCES}

Ackerman, D. (2004). An alchemy of mind. New York: Scribner.

Andersen, C. (2004). Learning in "as-if” worlds: Cognition in drama in education. Theory into Practice.

http://findarticles.com/p/articles/mi_m0NQM/is_4_43/ai_n8686066

Bell, C. C. (2012). Prevention in action: Promoting creative engagement in the elderly. Clinical Psychiatry News.

http://www.clinicalpsychiatrynews.com/views/prevention-in-action-b y-dr-carl-c-bell/blog/promoting-creative-engagement-in-the-elderly/3 d27f459c5.html

Fleshman, B., \& Fryrear, J. (1981). The Arts in therapy. Chicago: Nelson-Hall.

Loring, D. W. (1999). INS dictionary of neuropsychology. New York: Oxford University Press.

Jensen, E. (2010). Teaching high poverty kids using a high impact curriculum. Teaching with poverty in mind. http://www.jensenlearning.com/news/teaching-high-poverty-kids-usi ng-a-high-impact-curriculum/teaching-with-poverty-in-mind

Malchiodi, C. (2006). Expressive therapies: History, theory and practice. In C. Malchiodi (Ed.), In expressive therapies (pp. 1-15). New York: The Guilford Press.

Martin, S. (1977). Developmental drama for brain-Damaged children. Communication Education, 26, 208-213. doi:10.1080/03634527709378230

McNiff, S. (1981). The arts and psychotherapy. Springfield, IL: Thomas.

Munger, D. (2007). Is theater the ultimate brain fitness product? Cognitive Daily.

http://scienceblogs.com/cognitivedaily/2009/07/is_theater_the_ultim ate_brain_1.php

Pinker, S. (1997). How the mind works. New York: W. W. Norton \& Company.

Scheff, T. J. (2001). Catharsis in healing, ritual, and drama. Lincoln, NE: iUniverse.com

University of Liverpool (2006). Reading shakespeare has dramatic effect on human brain.

http://www.physorg.com/news85664210.html 